This is a self-archived - parallel published version of this article in the publication archive of the University of Vaasa. It might differ from the original.

\title{
Increasing rigor and relevance in service research through ethnography
}

Author(s): von Koskull, Catharina

Title: Increasing rigor and relevance in service research through ethnography

Year: $\quad 2020$

Version: Accepted manuscript

Copyright (C)2020 Emerald Publishing Limited. This manuscript version is made available under the Creative Commons AttributionNonCommercial 4.0 International (CC BY-NC 4.0) license, https://creativecommons.org/licenses/by-nc/4.o/

\section{Please cite the original version:}

von Koskull, C., (2020). Increasing rigor and relevance in service research through ethnography. Journal of services marketing. https://doi.org/10.1108/JSM-03-2019-0143 


\section{Increasing rigor and relevance in service research through ethnography}

\begin{tabular}{|r|l|}
\hline Journal: & Journal of Services Marketing \\
\hline Manuscript ID & JSM-03-2019-0143.R1 \\
\hline Manuscript Type: & Article \\
\hline Keywords: & ethnography, field study, qualitative research \\
\hline \multicolumn{2}{l}{} \\
\end{tabular}

SCHOLARONE ${ }^{\text {M }}$

Manuscripts 


\section{Increasing rigor and relevance in service research through ethnography}

"All of us want rigor in our research, and some seem to believe that that means using the latest or most complicated method. I disagree." (McAlister, 2016:565)

\section{Introduction}

McAlister is speaking to a quantitatively oriented audience - as he questions what he sees as an inflation of using one kind of statistical method (structural modelling) over another (regression modelling) as a necessary condition to get marketing research published. I believe that $A L L$ researchers independent of tribe want to produce rigorous research and I agree with McAlister that rigorous does not refer to newness or complicatedness, but rather to thoroughness and accuracy, or - in qualitative terminology - authenticity. Rigor and also relevance are central and important research quality criteria and often these two are referred to as being mutually exclusive. In this viewpoint I argue for and illustrate how traditional ethnography as an established methodology that is neither 'innovative' nor 'complicated' can promote and strengthen both rigor and relevance in qualitative service research and thereby further advance this area of research.

Originating from anthropology, ethnography is a way of doing and representing research that can be applied in any discipline and study interested in learning about humans and experiences. Pioneers such as Malinowski, Boas and Mead were influential in developing this approach that involved going to the source and becoming immersed in the world of others (see e.g. Schwartzman, 1993). The term ethnography refers both to a particular research methodology and to its eventual outcome; a written product. In a broad sense, this approach is based on an emergent logic that includes fieldwork using a variety of research techniques - primarily observation - over an extended period of time. The approach emphasizes and generates descriptive, detailed, contextual and real-time data, including that of the seemingly insignificant, the mundane and the taken-for-granted (see e.g. Davies, 2005).

Ethnography has been utilized more in organization studies and management than in marketing and consumer research, although ethnographies can be found in this latter area as well, primarily in Journal of Consumer Research and studies on consumer culture, see e.g. Maciel and Wallendorf, 2017; Scott, Cayla and Cova, 2017 and Woerman and Rokka, 2015. Although recent ethnographies are by and large still lacking in service research literature, a few exceptions can be found in for example Journal of Service Research, see Hill, Capella, Rapp and Gramercy Gentlemen, 2016 and in Journal of Service Management, see Vink, Edvardsson, Wetter-Edman and Tronvoll, 2019. There, thus, seems to be much room for ethnographic contributions in service research. Next, I discuss some central ethnographic aspects and assumptions that I 
believe make this research methodology a suitable approach for further advancing rigor and relevance in service research.

\section{Rigor}

I suggest the following three ethnographic aspects in particular can further increase rigor in service research: i) fieldwork, ii) prolonged time in the field, and iii) sensitivity to language and cultural codes. Despite the growing variety of ethnographic genres ${ }^{1}$ these assumptions seem to be universal.

\section{Ethnography relies on direct, firsthand experience and embodied research in the field}

To do ethnography researchers have to leave their 'ivory towers' and go out into the field, to the settings of those who are studied, irrespective of whether that entails going across the street or to the other side of the globe. van Maanen (2010:242) claims that this premise is "not up for grabs. One becomes an ethnographer by going out and doing it (and writing it up). Fieldwork of the immersive sort is by and large definitional of the trade." Indeed, this almost obsessive focus on studying and gathering in-depth data about human behavior and experiences where and while they naturally occur is the trademark of ethnography. Through this immersion in the field, in the situational context, and with the urge to 'walk in the shoes' of those studied, the ethnographer assumes it's possible to generate knowledge from within, from emic perspectives, and to interpret and understand (at least partially) the meaning-making by those studied. Geertz famously called this way of generating rich accounts 'thick descriptions". Thus, this firsthand experience of the daily lives and situations of those researched goes beyond relying solely on interviews, which also fosters capturing interesting differences between saying and doing, as well as distinguishimg between "operational" and "presentational data" (van Maanen, 1979). Operational data is the talk, conversations and actions the fieldworker observes in the field and the presentational data concern that which the informants strives to maintain or enhance in the eyes of the fieldworker.

From my own experience these differences are often captured in ethnography. For example, in a field study at a bank where I investigated the service innovation process from the initial phases to launch, I captured several situations where the development managers' sayings and doings substantially differed. Among other things, I was interested in understanding how much the customers were considered in developing the service. In a conversation just after the service was launched I asked the project manager how much the customers' wants and preferences had been guiding the development work. I was told that to the best of the manager's memory the project considered the customer all the way through the entire process "the customer had been their guiding star". However, during the field study and fifty-four project meetings that I had observed, the customer was briefly considered in less than ten of these.

\footnotetext{
${ }^{1}$ Structural -, interpretative -and critical ethnographies are examples of different ethnographic genres (see e.g. Cunliffe, 2010 and van Maanen, 2010).
} 


\section{Prolonged time in the field}

Another ethnographic aspect is to spend prolonged time in the field.

Ethnography is not a quick dip into a research site using surveys and interviews, but an extended period time in which the ethnographer immerses herself in the community she is studying: interacting with community members, observing, building relationships, and participating in community life (Cunliffe, 2010:227).

Entering into the field the ethnographer is initially greeted with a large amount of suspicion, such as; Why are you here? What are you doing, inspecting me? Where do you come from, who has sent you? And, rightfully so. It takes time to gain trust and build rapport with those researched, which is central for generating authentic pictures and stories about the field. Exactly how long cannot be determined in advance - although some suggest that a minimum of 12 months is needed in the field (Alvesson and Deetz, 2000). To become an insider is in my view neither possible nor desirable. Nevertheless, as an 'outsider' the ethnographer can become a kind of a "member" of the community being studied.

One example of how time and engagement in the field 'payed off' is when I was doing fieldwork in an elderly care home. After some months of regularly participating in the morning routines with different shifts of care workers, my name, all of a sudden, started to appear listed on the ward's white board among the names of the other care workers. To write the names of the care workers present and responsible for a particular ward was a daily team ritual and to me this was an explicit sign that I'd been "accepted" as some kind of member of the group. Another example is from a conversation I had with the care home manager about the elderly's reactions and views about me walking up and down the corridors, chitchatting and interacting with the elderly and the manager simply concluded that "you are one of us now" - this also served as a wake-up call that it was time to leave the field.

In addition to building trust, Arnould and Wallendorf (1994) suggest this longer time in the field increases the possibility to capture spontaneous events or moments in the everyday lives and situations studied. However, events that really do influence people's lives and behavior are often hidden to the ethnographer (van Maanen, 1979). It's safe to say that the degree of revelatory insights that a longer time of fieldwork brings differs depending on the studied setting, context and the relationships between the researcher and participants.

To generate rigor in the sense of thoroughness and accuracy/authenticity, it's important that ethnographic stories include as many different voices as possible, thus it's important to capture those consumer voices that are not well heard. In this regard, the extended period in the field can help to identify less visible participants and encourage them to participate in the research. The selection - or rather access to 'voices' is never one-way, we need to remember that the ethnographer is often as much selected by the participants or community members as the other way around (Davies, 2005). 


\section{Sensitivity to 'local' cultural language and codes}

The above assumptions of immersion into the field for a longer period of time help the researcher to decipher everyday cultural codes and to learn the language of those studied. Learning not only the language as such, but also more importantly the underlying meanings. Language is considered by the ethnographer as being "intrinsically tied to context and human activity" (Blommaert, 2005, p. 233). To focus on how (and why) participants express themselves the way they do in specific situations and circumstances is crucial in order to understand the participant's experiences and how she makes sense of it. Thus, to translate the field work into a credible story(-ies), the researcher needs to be sensitive to "speech-in-action". Cunliffe (2010) makes a distinction between language and talk and sees the former as "jargon, common phrases and words, technical language", and the latter as those "stories, narratives, metaphors, gossip and jokes" expressed by the community members (ibid, p. 229). The language used guides the ethnographer in developing knowledge and is a key to developing theoretical insights.

\section{Relevance}

To create relevant service research is to generate meaningful - and even useful research - that makes sense not only to academics, but to consumers, organizations, communities and societies. The central ethnographic premises of flexibility and reflexivity, I think, can in particular contribute to such relevance.

\section{Flexibility}

Researchers embarking on ethnography have to deal with a lot of uncertainties - especially in the beginning of the fieldwork before the researcher 'begins to find her feet'. As van Maanen (1988) vividly expresses it:

we move among strangers while holding [ourselves] in readiness for episodes of embarrassment, affection, misfortune, partial or vague revelation, deceit, confusion, isolation, warmth, adventure, fear, concealment, pleasure, surprise, insult, and always possible deportation (van Maanen, 1988: 2).

Thus, ethnography cannot be programmed. When the researcher is doing research in settings where she has little power or control, and where she may have little prior knowledge, the research cannot be rigidly planned in advance. Ethnography (and ethnographers) cannot be put in a straightjacket. Fieldwork is filled with the unexpected and therefore this approach is openended and flexible. This flexibility is also one of the key strengths with ethnography as this facilitates relevance in the sense of discovery and identification of newer ideas, thoughts, and the reconstruction of theories-in-use (Lofland, 1995).

\section{Reflexivity}

As we cannot step out of ourselves, research is always a product of our interpretations. "Thus, the idea that measurements, observations, the statements of interview subjects and the study of secondary data such as statistics or archival data have an unequivocal or unproblematic 
relationship to anything outside the empirical material is rejected on principle" (Alvesson and Sköldberg, 2018:11). Reflexivity is a key aspect in developing knowledge in general and perhaps even more so in ethnography. In a broad sense reflexivity means a turning back on oneself (Davies, 2005), a kind of process of critically thinking about how one thinks and tells stories. A continuous curiosity fosters the reflective mind to pay attention to the plausibility of those interpretations that are stacking up over the course of a field study. Interpretation does not take place in a vacuum or ideology-free space and there is no such thing as a value-free researcher (Alvesson and Sköldberg, 2018). How we see things (as well as hear, feel, taste) are filtered through our history of experiences of living and being, our ideals and values. This means that to learn about others and to generate credible stories about others' lives and behavior we need to keep an open and reflexive mindset throughout the entire research process. Hence, ethnography is not only about figuring out how we produce knowledge or create credible stories, it is also about who you are as an ethnographer and, increasingly so, I think, to whom you produce stories, who is the potential audience. Ethnography insists on asking these kinds of questions. Not until we start to rigorously contemplate and attend to these issues can we produce relevant service research.

\section{Conclusions}

In conclusion, ethnography is about understanding human experience ... by studying events, language, rituals, institutions, behaviors, artifacts, and interactions (Cunliffe, 2010:227). It differs from other approaches to research in that it requires the researcher to immerse herself into the field for a longer period of time, to be sensitive and to learn the language of those studied. These ethnographic features reject decontextualized science and, rather promote rigor; thoroughness and authenticity in our stories. Ethnography also insists on flexibility and above all nurtures a reflexive mind, two central aspects that, in addition to rigor, contribute to meaningful and relevant stories.

At the risk of preaching to the already converted (after all, this is a special issue of qualitative research methodologies most likely read by qualitative researchers), I encourage more service researchers to engage in ethnographic research and to realize its potential to increase both rigor and relevance in our service research endeavors.

\section{References}

Alvesson, M. and Deetz, S. (2000), Doing Critical Management Research, Sage Publications, London.

Alvesson, M. and Sköldberg, K. (2018), Reflexive Methodology: New Vistas for Qualitative Research, $3^{\text {rd }}$ ed., Sage Publications, London.

Arnould, E. and Wallendorf, M. (1994), "Market-oriented ethnography: interpretation building and marketing strategy formulation", Journal of Marketing, Vol. 31 No 4 (November), pp. 484-504.

Blommaert, J. (2005), Discourse: a critical introduction, Cambridge University Press, Cambridge. 
Cunliffe, A.L. (2010), "Retelling tales of the field: in search of organizational ethnography 20 years on", Organizational Research Methods, Vol. 13 No 2 (April), pp. 224-239.

Davies, C. (2005), Reflexive Ethnography: A Guide to Researching Selves and Others, Routledge, London.

Hill, R.P., Capella, M.L., Rapp, J.M. and Gramercy Gentlemen (2016), “Antiservice as guiding maxim: tough lessons from a maximum security prison", Journal of Service Research, Vol. 19 No. 1 , pp. 57-71.

Lofland J. (1995), "Analytic Ethnography: features, fallings, and futures", Journal of Contemporary Ethnography, Vol. 24 No. 1 (April), pp. 30-67.

Maciel, A. F. and Wallendorf, M. (2017), "Taste engineering: an extended consumer model of cultural competence constitution", Journal of Consumer Research, Vol. 43, pp. 726-746.

McAlister, L. (2016), "Rigor versus method imperialism", Journal of the Academy of Marketing Science, Vol. 44, pp. 565-567.

Schwartzman, H.B. (1993), Ethnography in Organizations, Qualitative Research Methods Series 27, Sage Publications, Thousand Oaks, CA

Scott, R., Cayla, J. and Cova, B. (2017), "Selling pain to the saturated self", Journal of Consumer Research, Vol. 44 No. 1, pp. 22-43.

van Maanen, J. (2010), “A song for my supper: more tales of the field", Organizational Research Methods, Vol. 13 No 2 (April), pp. 240-255.

van Maanen, J. (1988), Tales of the Field: On writing Ethnography, The University of Chicago Press, Chicago.

van Maanen, J. (1979), “The Fact of Fiction in Organizational Ethnography”, Administrative Science Quarterly, Vol. 24 No. 4 (December), pp. 539-550.

Vink, J., Edvardsson, B.,Wetter-Edman, K. and Tronvoll, B. (2019), "Reshaping mental models: enabling innovation through service design”, Journal of Service Management, Vol. 30 No 1, pp.75-104.

Woermann, N. and Rokka, J. (2015), “Timeflow: how consumption practices shape consumers' temporal experiences”, Journal of Consumer Research, Vol. 41 No. 6, pp. 1486-1508. 